GRASAS Y ACEITES 66 (2)

April-June 2015, e078

ISSN-L: 0017-3495

doi: http://dx.doi.org/10.3989/gya.0828142

\title{
Determination of pesticide residues in olives by liquid extraction surface analysis followed by liquid chromatography/tandem mass spectrometry
}

\author{
M.C. Gómez-Almenar ${ }^{\bowtie}$ and J.A. García-Mesa
}

IFAPA Centro Venta del Llano. Ctra. Bailén-Motril km. 18.5. 23620 Mengíbar. Jaén. Spain

${ }^{\square}$ Corresponding author: maika4@msn.com

Submitted: 20 August 2014; Accepted: 13 January 2015

\begin{abstract}
SUMMARY: Nowadays, pesticides are essential in modern agriculture for crop protection, however, this use supposes a potential risk for human health and the environment. Traditional techniques of pesticide determination require the use of laborious and complex extraction methods to separate pesticides from the matrix, above all in fatty matrices like olives. For this reason, a new simple, rapid, cheap and selective method for the extraction and quantification of the most frequently used pesticides in olive growing has been developed. Pesticide determination was carried out by ultra-performance liquid chromatography (UPLC) coupled with triple-quadrupole tandem mass spectrometry (MS/MS). Mean recoveries were found in a range between 73 and $114 \%$ with relative standard deviations lower than $20 \%$ in most pesticides evaluated and the limits of detection ( $L O D$ s) and quantification ( $L O Q \mathrm{~s}$ ) were lower than $4 \mu \mathrm{g} \cdot \mathrm{kg}^{-1}$ and $8 \mu \mathrm{g} \cdot \mathrm{kg}^{-1}$, respectively. Finally, this method was applied to the analysis of 25 olive samples where Dimethoate and Terbuthylazine were detected in some cases, but their results were lower than $15 \mu \mathrm{g} \cdot \mathrm{kg}^{-1}$.
\end{abstract}

KEYWORDS: Food analysis; Liquid extraction; Olives; Pesticide residues; UPLC-MS/MS

RESUMEN: Determinación de residuos de plaguicidas en aceitunas empleando análisis por extracción líquida de la superficie seguida por cromatografía líquida l espectrometría de masas en tándem. Hoy en día los pesticidas son esenciales en la agricultura moderna para la protección de los cultivos pero su uso supone un riesgo para la salud y el medio ambiente. Las técnicas tradicionales de determinación de pesticidas requieren el uso de métodos de extracción complejos a fin de separar los pesticidas de la matriz, sobre todo en matrices grasas como las aceitunas. Por ello, se ha desarrollado un nuevo método simple, rápido, barato y selectivo para la extracción y cuantificación de los pesticidas más frecuentemente utilizados en el cultivo del olivo, empleando cromatografía líquida de ultra-resolución (UPLC) acoplada a espectrometría de masas (MS/MS). Las recuperaciones alcanzadas variaron entre el 73 y 114\% obteniendo desviaciones estándar relativas inferiores al 20\%. Los límites de detección (LD) y cuantificación (LQ) fueron inferiores a 4 y $8 \mu \mathrm{g} \cdot \mathrm{kg}^{-1}$, respectivamente. Finalmente, este método fue aplicado en 25 muestras de aceitunas donde se detectaron Dimetoato y Terbutilazina en algunos casos pero con valores inferiores a $15 \mu \mathrm{g} \cdot \mathrm{kg}^{-1}$.

PALABRAS CLAVE: Aceitunas; Análisis de alimentos; Extracción líquida; Residuos de pesticidas; UPLC-MS/MS

Citation/Cómo citar este artículo: Gómez-Almenar MC, García-Mesa JA. 2015. Determination of pesticide residues in olives by liquid extraction surface analysis followed by liquid chromatography/tandem mass spectrometry. Grasas Aceites 66 (2): e078. doi: http://dx.doi.org/10.3989/gya.0828142.

Copyright: (C) 2015 CSIC. This is an open-access article distributed under the terms of the Creative Commons Attribution-Non Commercial (by-nc) Spain 3.0 Licence. 


\section{INTRODUCTION}

Olive oil is the most important edible vegetable oil in the Mediterranean countries and is the base of the well-known Mediterranean diet. This popularity is due to its manifest sensorial characteristics and its healthy nutritional properties. In recent years, many studies have repeatedly demonstrated its role in the reduction in cardiovascular diseases, the prevention of atherosclerosis, the improvement of the nervous system and bone development, antioxidant and anti-aging properties or the prevention of tumours (Covas, 2007; Ruiz-Canela and Martínez-González, 2011).

Pesticides and crop protection products are commonly used in modern agriculture. Unfortunately, the misuse of pesticides can lead to food security issues, risking the health of consumers and the environment. Virgin olive oil is a product which, potentially, can contain pesticides if the processed olives contain this type of contaminants. Recent studies have analyzed the presence of pesticide residues in olive oil, olives and even in their washing water (Aramendía, et al., 2007; Cunha, et al., 2007a; Cunha, et al., 2007b; Cunha, et al., 2007c; GarcíaReyes, et al., 2007a; Guardia Rubio, et al., 2006; Guardia Rubio, et al., 2007a; Guardia Rubio, et al., 2007b; Guardia Rubio, et al., 2007c). The reason for the possible contamination by pesticides is mainly due to an inappropriate use of the products by farmers, who could use high doses of pesticides or also do not respect the guidelines for their usage, resulting in a contamination that could be significantly favored if flight olives are mixed with soil olives during harvesting. There are many types of pesticides used in olive cultivation, but in recent years the pesticides chiefly applied have been Diuron, Terbuthylazine, Endosulfan, Oxyfluorfen, Glyphosate, Diflufenican, Dimethoate, Phosmet and Chlorpyrifos. The use of Endosulfan, Diuron and Terbuthylazine has been restricted in certain areas but they have been occasionally found in some samples since they remain in the soil after application (Ferrer, et al., 2005; Guardia Rubio, et al., 2007c). Other herbicides such as Oxyfluorfen and Diflufenican or insecticides such as Phosmet, Chlorpyrifos and Dimethoate have high adsorption coefficients and therefore their decomposition is difficult, generating an environmental concern (Long, et al., 2005; Yuzhou and Xin, 2012).

Traditional methods for the determination of residues in olives or olive oil involve a lengthy analysis, especially in the separation of pesticide residues in the matrix due to its high fat content. Moreover, these traditional methods require a large amount of organic solvents, which are expensive and generate considerable wastes. The extraction methods usually applied are matrix solid phase dispersion (MSPD), liquid-liquid extraction using different solvents, gel permeation chromatography (GPC) or solid phase extraction (SPE) (Ferrer, et al., 2005; García-Reyes, et al., 2007a; Guardia Rubio, et al., 2006; Guardia Rubio, et al., 2007c). All of them use different detectors for further analysis, such as flame ionization detector (FID), nitrogen-phosphorus detector (NPD) or electron capture detector (ECD) (Amvrazi and Albanis, 2006), and in the last ten years the use of mass spectrometry (MS) or time of flight mass analyzer (TOF) have become more common (Angioni, et al., 2011; Cervera, et al., 2012; GarcíaReyes, et al., 2007b; Koesukwiwat, et al., 2010).

The current trend in the new methods of pesticide determination is the development of rapid, inexpensive and simple procedures. The main feature of these procedures is the use of fewer steps of analysis and the absence of interferences for a correct determination. In addition, the isolated extract must also comprehend most of the pesticides in a simple analysis. Pesticide multi-residue analysis is now a challenge due to the low levels present in the samples and the wide variety and different chemical family they belong to. Strict limits of detection are required for the quantification of pesticide residues in food samples, and therefore the use of very sensitive, selective, robust and accurate technologies is required.

Nowadays, the most commonly used extraction method for pesticide determination in food matrices is the QuEChERS method (Quick, Easy, Cheap, Effective, Rugged and Safe), with different modifications depending on the fat content in the matrix (Lehotay, et al., 2010; Wilkowska and Biziuk, 2011). This method gives good results in terms of quality, speed, ease and cost. Thr method is based on a liquid-liquid extraction with $\mathrm{MeCN}$, followed by a cleaning step using several absorbents. The original procedure (Anastassiades, et al., 2003) has been modified using various versions but the acetate buffer version has become the official method for the AOAC as the AOAC Official Method 2007.1 (Lehotay, et al., 2005; Lehotay, et al., 2007) and the version using citrate buffer has been taken as standard method EN 15662 by the European Committee for Standardization (CEN) (European Committee for Standardization, 2013).

However, to our knowledge this method has not been reported in the scientific literature to determine the following collection of pesticides: Amitrole, Chlorpyrifos, Diflufenican, Dimethoate, Diuron, Terbuthylazine, Phosmet and Oxyfluorfen on the olive surface, and it has only been described as applied to olive oil or olives treated with another set of pesticides (Cunha, et al., 2007a; García-Reyes, et al., 2007a; Gilbert-López, et al., 2010a; GilbertLópez, et al., 2010b; Gilbert-López, et al., 2010c). Unfortunately, in recent years these compounds have been found in real samples of olives (Guardia Rubio, et al., 2007c) and olive oil (Ballesteros, et al., 
2006; Sánchez, et al., 2006), either above or below their Maximum Residue Levels (MRL) and their rapid determination is necessary.

If the olives are contaminated with pesticides, it is expected that they are found on the surface of them because of an incorrect use of pesticide or, more than likely, owing to the contact of the fruit with the ground previously treated with pesticides. For these reasons, in this paper we propose a new method for pesticide determination based on liquid extraction surface analysis of the olive surface.

Liquid extraction surface analysis coupled with infusion nano-electrospray high-resolution mass spectrometry and tandem mass spectrometry (MS/MS), has previously been applied to the qualitative determination of surface chemical residues resulting from the artificial spraying of selected fresh fruits and vegetables with a sample of representative pesticides (Eikel and Henion, 2011). The surface sample is automatically extracted by a robotic micropipette using a small volume (1-3 $\mu \mathrm{L})$ of solvent (80:20 methanolwater with $0.1 \%$ vol. acetic acid as a modifier) which was directly injected by infusion into the MS detector without chromatographic separation.

The aim of this paper was to develop a new simple, rapid, cheap and selective method for the extraction and quantification of the most frequently used pesticides in olive growing. For this purpose, a new method based on the liquid extraction surface analysis of olives was evaluated. In this method the whole surface of olives is extracted, and this extract is analyzed by LC-MS/MS. The method is simple, rapid and cheap, and was applied to the determination of 8 of the most important pesticides in olive-growing. The pesticides studied were three insecticides (Dimethoate, Chlorpyrifos and Phosmet) and five herbicides (Amitrole, Oxyfluorfen, Terbuthylazine, Diflufenican and Diuron). The levels of MRLs are shown in Table 1. The new method was evaluated using different solvents, times and speeds of extraction in order to choose the best possible analytical conditions for the multi-residue determination. The validation studies were applied and gave good results in spiked and real samples.

\section{MATERIALS AND METHODS}

\subsection{Reagents and materials}

All pesticide standards (purity higher than 99\%) were obtained from Sigma-Aldrich (Madrid, Spain). All solvents (viz.) acetonitrile (99.8\%), methanol (99.8\%), formicacid (puriss. $\sim 98 \%$ ) were LC/MS-grade and supplied by Sigma-Aldrich (Madrid, Spain). UV-Vis-grade acetone was purchased from SigmaAldrich (Madrid, Spain). Ultrapure water was produced by a Milli-Q Reference water purification system (Millipore, Bedford, MA, USA).

Stock standard solutions of individual compounds were prepared by exact weighing of $25 \mathrm{mg}$ of the compound followed by dissolution in $50 \mathrm{~mL}$ of $\mathrm{MeCN}$ and then stored at $-18^{\circ} \mathrm{C}$ in the dark.

A multi-compound working standard solution (1 $\mathrm{mg} \cdot \mathrm{L}^{-1}$ concentration of each compound) was prepared weekly with appropriate dilutions of the stock solutions with $\mathrm{MeCN}$ and stored at $4{ }^{\circ} \mathrm{C}$. This solution was used to prepare the calibration curves.

A multi-pesticide spiking solution was prepared by mixing appropriate dilutions of the stock solutions with MeCN:acetone (45:55) to obtain two concentration levels at 2 and $10 \mathrm{mg} \cdot \mathrm{L}^{-1}$. Then, $5 \mathrm{~mL}$ of each one of them were used to fortify two samples of $500 \mathrm{~g}$ of olives contained in a tray with two concentration levels of 20 and $100 \mu \mathrm{g} \cdot \mathrm{kg}^{-1}$ each.

\subsection{Apparatus}

An automatic shaker of oscillating movement Vibromatic, Selecta (Barcelona, Spain) was used to extract the pesticides from the olive samples.

TABLE 1. Pesticide residues at maximum residue levels $\left(\mathrm{mg} \cdot \mathrm{kg}^{-1}\right)$ allowed in the olive: EU-MRLs Regulation (EC) No 396/2005. MRLs updated on 18/04/14 (DG SANCO, 2014)

\begin{tabular}{|c|c|c|c|c|c|}
\hline Pesticides & $\begin{array}{c}C A S \\
\text { Registry Number }\end{array}$ & Molecular Formula & $\begin{array}{c}\log K_{o w} \\
\left(p H 7,20^{\circ} \mathrm{C}\right)^{1^{*}}\end{array}$ & $\begin{array}{l}\text { MRLs of Table } \\
\text { Olives }\left(\mathbf{m g} \cdot \mathbf{k g}^{-1}\right)\end{array}$ & $\begin{array}{l}\text { MRLs of Olives for Oil } \\
\text { Production }\left(\mathrm{mg} \cdot \mathrm{kg}^{-1}\right)\end{array}$ \\
\hline Diflufenican & $83164-33-4$ & C19H11F5N2O2 & 4.20 & $0.05^{2^{* *}}$ & 0.20 \\
\hline Chlorpyrifos & $2921-88-2$ & C9H11Cl3NO3PS & 4.70 & $0.05^{3 * *}$ & $0.05^{4^{* *}}$ \\
\hline Phosmet & $732-11-6$ & C11H12NO4PS2 & 2.96 & 3.00 & 3.00 \\
\hline Diuron & $10290-37-6$ & $\mathrm{C} 9 \mathrm{H} 10 \mathrm{Cl} 2 \mathrm{~N} 2 \mathrm{O}$ & 2.87 & $0.01^{5^{* *}}$ & $0.02^{6^{* *}}$ \\
\hline Terbuthylazine & $5915-41-3$ & C9H16ClN5 & 3.40 & $0.05^{7^{* *}}$ & $0.05^{8^{* *}}$ \\
\hline Dimethoate & $60-51-5$ & C5H12NO3PS2 & 0.704 & 2.00 & 2.00 \\
\hline Amitrole & $61-82-5$ & $\mathrm{C} 2 \mathrm{H} 4 \mathrm{~N} 4$ & -0.97 & 0.05 & 0.05 \\
\hline Oxyfluorfen & $42874-03-3$ & $\mathrm{C} 15 \mathrm{H} 11 \mathrm{ClF} 3 \mathrm{NO} 4$ & 4.86 & 1.00 & 1.00 \\
\hline
\end{tabular}

\footnotetext{
${ }^{*}$ The PPDB: Pesticide Properties Database. AERU. University of Hertfordshire. http://sitem.herts.ac.uk/aeru/footprint/index2.htm.
}

*** Indicates lower limit of analytical determination. 
A high speed vortex mixer Heidolph Reax Top (Nuremberg, Germany) was used to vortex-mix the vials prior to the chromatographic analysis.

\subsection{Instruments}

\subsubsection{Liquid Chromatography}

Chromatographic analyses were performed in a WATERS ACQUITY UPLC system (Waters, Manchester, UK) consisting of an Acquity UPLC binary solvent manager, an Acquity UPLC sample manager and an Acquity UPLC column heater. Chromatographic separation was performed using a Waters Acquity UPLC BEH C18 column $(2.1 \mathrm{~mm} \times 100 \mathrm{~mm})$ with $1.7 \mu \mathrm{m}$ particle size (Milford, MA, USA). The column was maintained at $40{ }^{\circ} \mathrm{C}$, with a mobile phase flow rate of $0.25 \mathrm{~mL} \mathrm{~min}{ }^{-1}$. The mobile phase contained water (A) and $\mathrm{MetOH}$ (B) both with $0.1 \%$ formic acid. A gradient elution was employed, starting at $10 \% \mathrm{~B}$ and rising linearly to $90 \%$ over $2 \mathrm{~min}$. The composition was held at $90 \% \mathrm{~B}$ for $2 \mathrm{~min}$ before being returned to the initial conditions of $10 \% \mathrm{~B}$, followed by re-equilibration for $1.5 \mathrm{~min}$ and giving a 5 -minute total cycle. The injection volume for each sample was $10 \mu \mathrm{L}$ in "full loop" modus and the temperature inside the sample manager was maintained at $10{ }^{\circ} \mathrm{C}$.

\subsubsection{Mass Spectrometry}

Mass detection was performed using an Acquity TQD tandem quadruple mass spectrometer (Waters, Manchester, UK), equipped with an electrospray ionization interface (ESI) and operating in the positive ion mode. The ion source was operated at $150{ }^{\circ} \mathrm{C}$ with a capillary voltage of $1.0 \mathrm{kV}$. Nitrogen was employed for both the dissolvent and cone gases at $650{ }^{\circ} \mathrm{C}$ and $50 \mathrm{~L} \cdot \mathrm{hr}^{-1}$, respectively. The mode of acquisition was multiple reaction monitoring (MRM) at an argon collision gas pressure of $3.5 \times 10^{-3}$ mBar. MRM conditions were optimized for each pesticide during infusion. Data acquisition and processing were performed using MassLynx 4.1 (Waters, Manchester, UK).

\subsection{Samples and spiking procedure}

\subsubsection{Samples}

Flight olives (cultivar Picual) were collected from the "Instituto Andaluz de Investigación y Formación Agraria, Pesquera, Alimentaria y de la Producción Ecológica IFAPA Centro 'Venta del Llano"' (Jaén, Spain). Olive fruits with a maturation degree of 4-5 were directly collected from trees and they were used as a starting material for preparing working samples: blank samples, spiked samples and matrix-matched calibration standards for validation studies.

\subsubsection{Spiking procedure}

$500 \mathrm{~g}$ of olive fruits were arranged on a small tray $(25 \mathrm{~cm}$ of diameter) for the olives to be divided into, at least, two or three layers. Then, $0.5 \mathrm{ml}$ of multi-compound pesticide spiking solution was sprayed onto the whole sample surface and let stand until the solvents were virtually evaporated. The olives were mixed in order to reach a random distribution and then were sprayed again. This process was repeatedly performed until all the olives were homogeneously sprayed with the pesticide spiking solution using a total volume of $5.0 \mathrm{~mL}$. This process was carried out at two spiking levels. The spiking solution was prepared using a $\mathrm{MeCN}$ : acetone (45:55) mixture to ensure both a correct adherence and a rapid evaporation.

\subsection{Liquid extraction surface analysis}

$30 \mathrm{~g}$ of olives were introduced into a Hybex stoppered borosilicate bottle (extraction flask) and then $30 \mathrm{~mL}$ of $\mathrm{MeCN}$ were added. After closing the flask, the bottle was shaken with an automatic shaker for 10 minutes at a speed of 750 oscillations per minute. A portion of the extract was collected with a syringe and filtered through a $0.2 \mu \mathrm{m}$ PTFEfilter. The filtrate $(1.0 \mathrm{~mL})$ was transferred to a vial and analyzed in the UPLC-MS/MS system. The extracts were pre-filtered through a filter paper of a pore size of $0.45 \mu \mathrm{m}$ under vacuum conditions when the samples contained a large amount of leaves, soil or sludge in order to facilitate their passage through the filter of $0.2 \mu \mathrm{m}$.

\subsection{Method performance}

The optimization study was carried out according to the univariate method. The precision and accuracy of the method were tested with spiked olive samples. Recoveries were determined for five replicates at two spiking concentrations $(0.02$ and $\left.0.1 \mathrm{mg} \cdot \mathrm{kg}^{-1}\right)$. Matrix-matched multi-level calibration standards were used for the calibration.

\section{RESULTS AND DISCUSSION}

\subsection{Optimization of LC-MS/MS conditions}

The optimization of the MS conditions for the determination of selected pesticides was performed by examining the spectra in "full scan" and MS/MS obtained for each compound. Firstly, experiments were directly conducted by infusion of the MS standards in order to optimize the cone voltage conditions necessary to maximize the signal for each molecule. Then, the collision energy required for the fragmentation of the molecules was optimized. 
The optimization of the precursor ion and product ions was carried out by the injection of $7 \mu \mathrm{L}$ of the individual pesticide standard solution $\left(4 \mu \mathrm{g} \cdot \mathrm{mL}^{-1}\right.$ in $\mathrm{MeCN}$ ) directly into the mass spectrometer with a flow rate of $0.25 \mathrm{~mL} \cdot \mathrm{min}^{-1}$. Different cone voltages were applied and when the optimal cone voltage was found, different collision energies were studied. The collision energy was adjusted to produce the highest intensity for the main fragment. The dwell time parameter was evaluated for each pesticide in the range of 5 to $200 \mathrm{~ms}$.

Finally, the most intense transition was used as a quantifier while the other transition with less intensity was used as a qualifier peak for the confirmation analysis. The optimal conditions are summarized in Table 2.

\subsection{Optimization of extraction conditions}

Four variables were studied to obtain the best conditions for the liquid extraction surface analysis method: extraction solvent, sample/solvent ratio, extraction time and oscillation speed. The matrix effect and the number of necessary extraction steps were evaluated as well.

\subsubsection{Matrix-matched calibration and Matrix Effect}

The matrix effects in LC-MS with an electrospray ionization source must be studied in complex matrices like olives. This effect is produced when other compounds present in the matrix can interfere in the ionization of the target compound. Interferences can be caused by a decrease or enhancement of the analytical signal, which would cause difficulties concerning the correct detection and quantification of pesticides.

In all the methods previously described in the literature, olives are first crushed and then extracted with an appropriate solvent. These procedures provide a co-extraction of variable amounts of olive oil, which must be later removed as much as possible by applying of different clean up steps.

In the new proposed method, the olives are not crushed so that there should not be a co-extraction of oil. But considering that the liquid extraction surface analysis extract is directly analyzed without any cleaning steps, this potential effect has to be elucidated.

At first, it was assumed that the matrix effect in the surface analysis method would be low. However, other components present on the olive surface (waxes, triglycerides, pigments, etc.) might be coextracted during extraction and incorporated into the final extract, affecting the correct detection of the target compounds. For this reason, the matrix effect was tested by comparing the slope of the calibration curves in matrix-matched or in the solvent. Then, the matrix/solvent slope ratio for each pesticide was calculated. Calibration curves in the matrix or in the solvent were made with the use of standards prepared at the concentrations of $0,10,25$, $50,75,100,150$ and $300 \mathrm{ng} \cdot \mathrm{mL}^{-1}$.

The potential matrix effect can be quantified by comparing the slopes of the calibration curves prepared with or without the matrix. Taking into account the ratio between them, a classification of the matrix effect can be carried out, so that

Matrix Effect=100 * [1- (slope matrix / slope solvent)]

Based on the classification studied by B. Kmellár (Kmellár, et al., 2008), and depending on the decrease /increase in the slope, different kinds of matrix effects could be considered: soft matrix effect, when the ratio is lower than $20 \%$; moderate, from 20 to $50 \%$; or strong when it is higher than $50 \%$ since this could mask the correct detection of the pesticides.

Chromatographic signal suppression was noted in all the pesticides. The matrix effect for some pesticides like Diflufenican, Terbuthylazine or Diuron could be considered as soft matrix effect, and other

TABLE 2. Pesticides analyzed by ${ }^{*}$ LC-ESI-MS/MS positive mode, molar masses, MRM parameters, ion ratios and retention time data

\begin{tabular}{|c|c|c|c|c|c|c|c|c|c|c|}
\hline \multirow[b]{2}{*}{ Pesticide } & \multirow[b]{2}{*}{$\begin{array}{l}\text { Molar } \\
\text { Mass }\end{array}$} & \multirow[b]{2}{*}{$\begin{array}{c}\text { Cone } \\
\text { Voltage (V) }\end{array}$} & \multirow[b]{2}{*}{$\begin{array}{l}\text { Precursor } \\
\text { ion }(\mathrm{m} / \mathrm{z})\end{array}$} & \multicolumn{2}{|c|}{$\begin{array}{l}1^{\text {st }} \text { Transition } \\
\text { (Quantification) }\end{array}$} & \multicolumn{2}{|c|}{$\begin{array}{c}2^{\text {nd }} \text { Transition } \\
\text { (Confirmation) }\end{array}$} & \multirow[b]{2}{*}{$\begin{array}{c}\text { Ion } \\
\text { Ratio }\end{array}$} & \multirow[b]{2}{*}{$\begin{array}{c}\text { Dwell } \\
\text { Time (ms) }\end{array}$} & \multirow[b]{2}{*}{$\begin{array}{c}t_{\mathrm{R}} \\
\text { (min) }\end{array}$} \\
\hline & & & & $\begin{array}{c}\text { Product } \\
\text { ion }(\mathrm{m} / \mathrm{z})\end{array}$ & $\begin{array}{c}\text { Collision } \\
\text { Energy (eV) }\end{array}$ & $\begin{array}{l}\text { Product } \\
\text { ion }(\mathrm{m} / \mathrm{z})\end{array}$ & $\begin{array}{c}\text { Collision } \\
\text { Energy (eV) }\end{array}$ & & & \\
\hline Amitrole & 84.04 & 45 & 85.06 & 43.30 & 16.00 & 57.30 & 14.00 & 0.51 & 50 & 0.99 \\
\hline Dimethoate & 229.00 & 25 & 230.00 & 199.00 & 25.00 & 125.10 & 24.00 & 1.41 & 50 & 3.01 \\
\hline Phosmet & 317.00 & 25 & 318.04 & 160.10 & 16.00 & 133.20 & 52.00 & 25.00 & 20 & 3.36 \\
\hline Diuron & 232.02 & 40 & 233.05 & 72.20 & 31.00 & 160.00 & 33.00 & 28.00 & 15 & 3.36 \\
\hline Terbuthylazine & 229.11 & 35 & 230.22 & 174.10 & 20.00 & 96.20 & 33.00 & 6.01 & 20 & 3.43 \\
\hline Diflufenican & 394.07 & 48 & 395.22 & 266.20 & 44.00 & 246.20 & 44.00 & 1.29 & 20 & 3.65 \\
\hline Oxyfluorfen & 361.70 & 33 & 362.00 & 316.00 & 10.00 & 237.50 & 20.00 & 15.85 & 20 & 3.78 \\
\hline Chlorpyrifos & 348.93 & 33 & 350.03 & 198.25 & 23.00 & 107.00 & 56.00 & 0.62 & 20 & 3.94 \\
\hline
\end{tabular}

*Liquid Chromatography coupled with mass spectrometry working in positive electrospray ionization (ESI). 
compounds present in the matrix would have a small impact in the correct determination of these pesticides. However, other pesticides like Dimethoate, Phosmet and Chlorpyrifos should always be calibrated with the matrix, because its matrix effect was greater than $30 \%$. The matrix effects for Oxyfluorfen and Amitrol were extremely strong (more than 60\%) and it was very difficult to build a good calibration curve for these pesticides. As a conclusion, all the pesticides were determined from the standard matrix-matched calibrations. The results can be observed in Table 3.

\subsubsection{Selection of the extraction solvent}

In spite of the fact that $\mathrm{MeCN}$ is the most commonly used solvent for pesticide extraction in the analysis of olives, several potential solvents (or mixtures) were evaluated: $\mathrm{MeCN}$, MetOH, $\mathrm{MeCN} / \mathrm{MetOH}(80: 20 \mathrm{v} / \mathrm{v})$ and water/ MetOH $(1: 3 \mathrm{v} / \mathrm{v})$. In order to select the best extraction solvent, the amount (weight) of matrix extracted by each solvent was studied as a first approach. For this purpose, the amount of solvent used for each extraction was $30 \mathrm{~mL}$ and the amount of olives selected was $30 \mathrm{~g}$. The extraction was carried out by manual shaking for 5 minutes.

The absolute amount of extract obtained from each solvent was tested from four types of extraction solvents. MetOH extracted $13.2 \mathrm{mg}$ of matrix per $\mathrm{g}$ of olives compared to $4.6 \mathrm{mg}$ of matrix that the solvent mixtures extracted or $2.5 \mathrm{mg}$ extracted by $\mathrm{MeCN}$ (values calculated as a solid weight after vacuum evaporation of an aliquot of the extract). With these results, MetOH initially could be discarded because the amount of matrix extracted by this solvent was much greater than that found for the rest of solvents. Nevertheless, MetOH was not discarded in order to evaluate its performance from other points of view.
The next parameter evaluated was the recovery of each solvent by extracting samples spiked at $100 \mu \mathrm{g} \cdot \mathrm{kg}^{-1}$. The best recoveries were obtained when $\mathrm{MeCN}$ was used in the extraction. Poor recoveries were obtained using the other three extraction solvents in the study, which were not able to reach $30 \%$ and were therefore discarded.

Finally, the optimization of the other variables in the extraction method continued with the use of $\mathrm{MeCN}$ as extraction solvent.

\subsubsection{Selection of the solvent/sample ratio}

The next variable studied was the amount of solvent to extract the analytes, i.e., the solvent/sample ratio. For this purpose, $30 \mathrm{~g}$ of spiked samples $\left(100 \mu \mathrm{g} \cdot \mathrm{kg}^{-1}\right)$ were extracted during $5 \mathrm{~min}$ by manual shaking in vessels containing 30,90 or $150 \mathrm{~mL}$ of $\mathrm{MeCN}$ (w/v ratio $1 / 1,1 / 3$ and $1 / 5$, respectively). A sample/solvent ratio of 1:1 was selected because increasing the solvent volume did not produce a better extraction yield.

\subsubsection{Optimization of time and speed of oscillation}

In order to automatize the extraction step in order to improve the repeatability of the process, the use of an automatic shaker was studied. Two experimental variables were studied: speed of oscillation and extraction time. For this purpose, samples spiked at the $100 \mu \mathrm{g} \cdot \mathrm{mL}^{-1}$ level were analyzed, and the obtained recoveries were compared. Firstly, 5 speeds were tested using 5 minutes in each extraction: 100, 250, 500, 750 and 990 oscillations per minute (opm). Recoveries were shown to rise as the speed increased until a maximum speed of $750 \mathrm{opm}$. Recoveries of the tested pesticides decreased dramatically when the speed of oscillation was higher than $750 \mathrm{opm}$. Once the speed of $750 \mathrm{opm}$ had been selected, the extraction time was optimized.

TABLE 3. Calibration parameters of matrix and solvent curves. The calibration range was $10-300 \mathrm{ng} \cdot \mathrm{mL}^{-1}$

\begin{tabular}{|c|c|c|c|c|c|c|c|}
\hline \multirow[b]{2}{*}{ Pesticides } & \multicolumn{2}{|c|}{ Solvent Curve } & \multicolumn{2}{|c|}{ Matrix Curve } & \multirow[b]{2}{*}{$\begin{array}{c}\text { Ratio Slope } \\
\text { (Matrix/Solvent) }\end{array}$} & \multirow[b]{2}{*}{$\begin{array}{c}\text { Matrix } \\
\text { Effect }\end{array}$} & \multirow[b]{2}{*}{$\begin{array}{c}\text { Type of } \\
\text { Effect }\end{array}$} \\
\hline & Slope & $\begin{array}{l}\text { Correlation } \\
\text { Coefficient }\end{array}$ & Slope & $\begin{array}{l}\text { Correlation } \\
\text { Coefficient }\end{array}$ & & & \\
\hline Diflufenican & 84.20 & 0.9988 & 72.04 & 0.9984 & 0.86 & $14 \%$ & Soft \\
\hline Chlorpyrifos & 16.81 & 0.9971 & 10.28 & 0.9933 & 0.61 & $39 \%$ & Moderate \\
\hline Phosmet & 333.92 & 0.9980 & 217.81 & 0.9995 & 0.65 & $35 \%$ & Moderate \\
\hline Diuron & 321.87 & 0.9986 & 256.07 & 0.9986 & 0.80 & $20 \%$ & Soft \\
\hline Terbuthylazine & 4212.60 & 0.9985 & 3949.44 & 0.9959 & 0.94 & $6 \%$ & Soft \\
\hline Dimethoate & 302.26 & 0.9997 & 205.89 & 0.9996 & 0.68 & $32 \%$ & Moderate \\
\hline Amitrole & 30.69 & 0.9954 & 7.63 & 0.9991 & 0.45 & $55 \%$ & Strong \\
\hline Oxyfluorfen & 14.32 & 0.9980 & 0.39 & 0.9587 & 0.03 & $97 \%$ & Strong \\
\hline
\end{tabular}

Five replicates were made for the standard solutions. Matrix effect expressed as ratio between slope matrix-matched and slope solvent calibration. 
For this purpose, 4 shaking times were tested: 1, 2, 5 and 10 minutes. It was noted that the recoveries increased according to an increase in time, reaching almost $100 \%$ recoveries after 10 minutes.

Finally, the effect of solvent/temperature during extraction was studied as well. Three temperatures were evaluated $\left(25,30\right.$ and $\left.35^{\circ} \mathrm{C}\right)$, while maintaining a constant speed of $750 \mathrm{opm}$ for $10 \mathrm{~min}$, but the respective recoveries did not show significant differences.

The final conditions of the liquid extraction surface analysis method were: $\mathrm{MeCN}$ as a solvent extraction in a 1:1 (w/v) ratio, and $10 \mathrm{~min}$ of extraction by shaking at $750 \mathrm{opm}$ using a solvent temperature of $25^{\circ} \mathrm{C}$. These results are summarized in Table 4 .

\subsubsection{Optimization of number of extractions}

In order to know if a single surface extraction was enough, or whether by applying a second extraction on the treated olives a greater amount of pesticides would be extracted, the recoveries of a successive extraction step were evaluated. The results are shown in Table 5. As can be seen, good recoveries were obtained, and reached a range from 70 to $99 \%$ for 6 of the 8 pesticides studied when a single extraction was applied. Recoveries between $73-102 \%$ were reached when a second extraction was used. It is noteworthy that the second extraction did not reach an appreciable amount of pesticides, and the remaining amount that could not be extracted with a single extraction step was 3\%. However, since it is a small and constant value, it could be considered that a single extraction is enough to reach good recoveries for the whole of the pesticides.

Unfortunately, Oxyfluorfen and Amitrole determination were not successful, and this is probably because this extraction method was not effective enough to extract these pesticides from the olive surface.

\subsection{Validation of the analytical method}

In order to validate the proposed method, selectivity, linearity, repeatability, recovery and limits of detection (LOD) and quantification (LOQ) were tested according to the criteria set by the EU guidelines SANCO/12571/2013 (DG SANCO, 2013).

The selectivity was evaluated as to the possible presence of peaks in blank samples, free of pesticides. The absence of peaks of the target pesticides in their retention times in the chromatograms belonging to blank extracts confirmed the selectivity of the method, and therefore, there were no false positives signals in the samples.

The linearity of the method was evaluated with matrix-matched calibration standards at seven concentration levels ranging from 10 to $300 \mathrm{ng} \cdot \mathrm{mL}^{-1}$. The seven-point-calibration curves in solvent or in matrix were constructed and compared at the

TABLE 4. Summary of variables studied to optimize the liquid extraction surface analysis method.

The variables finally selected were those that gave the highest recoveries of the pesticides studied

\begin{tabular}{|c|c|c|c|c|c|}
\hline & Variable Studied & Conditions & $\mathrm{mg} \cdot \mathrm{g}^{-1}$ matrix & Recovery range & Optimal variable $^{*}$ \\
\hline \multirow{4}{*}{ Extraction Solvent } & $\mathrm{MeCN}$ & $100 \%$ & 2.5 & $>40 \%$ & \multirow[t]{4}{*}{$\mathrm{MeCN}$} \\
\hline & MetOH & $100 \%$ & 13.2 & $<30 \%$ & \\
\hline & $\mathrm{MeCN} / \mathrm{MetOH}$ mixture & $80: 20(\mathrm{v} / \mathrm{v})$ & 4.6 & Values out of range & \\
\hline & Water/MetOH mixture & $1: 3(\mathrm{v} / \mathrm{v})$ & 4.6 & $<30 \%$ & \\
\hline \multirow{4}{*}{$\begin{array}{l}\text { Solvent/Sample } \\
\text { Ratio (weight/ } \\
\text { volume) }\end{array}$} & Ratio (w/v) & Sample Weight (g) & MeCN Volume (mL) & Recovery range $(\%)$ & Optimal variable \\
\hline & $1: 1$ & 30 & 30 & $44-78$ & \multirow[t]{3}{*}{ 1:1 ratio } \\
\hline & $1: 3$ & 30 & 90 & $13-80$ & \\
\hline & $1: 5$ & 30 & 150 & $19-75$ & \\
\hline \multirow{6}{*}{ Oscillation } & Oscillation speed (opm) & Recovery range (\%) & Oscillation time (min) & Recovery range $^{* *}(\%)$ & Optimal variable \\
\hline & 100 & $<10$ & 0 & $<10$ & 750 opm \\
\hline & 250 & $<50$ & 1 & $50-83$ & \multirow[t]{4}{*}{$10 \mathrm{~min}$} \\
\hline & 500 & $<70$ & 2 & $57-92$ & \\
\hline & 750 & $70-98$ & 5 & $83-97$ & \\
\hline & 990 & $37-50$ & 10 & $89-103$ & \\
\hline \multirow{4}{*}{$\begin{array}{l}\text { Solvent } \\
\text { Temperature }\left({ }^{\circ} \mathrm{C}\right)\end{array}$} & Variables & & & & Optimal variable \\
\hline & 25 & \multirow{3}{*}{\multicolumn{3}{|c|}{ No significant differences were found }} & 25 \\
\hline & 30 & & & & \\
\hline & 35 & & & & \\
\hline
\end{tabular}

*Final conditions of the liquid extraction surface analysis in bold.

**Excluding Oxyfluorfen and Amitrole. 
TABLE 5. Average recovery ( $\%), n=5$; RSD (\%) obtained by extraction of samples spiked at $100 \mu \mathrm{g} \cdot \mathrm{kg}^{-1}$, analyzed by ${ }^{*}$ LC-ESI-MS/MS positive mode in one or two extractions

\begin{tabular}{|c|c|c|c|c|c|}
\hline \multirow[b]{2}{*}{ Pesticide } & \multicolumn{2}{|c|}{$1^{\text {st }}$ Extraction $(30 \mathrm{~mL})$} & \multicolumn{2}{|c|}{$2^{\text {nd }}$ Extraction $(30 \mathrm{~mL})$} & \multirow[t]{2}{*}{ Overall (\%) } \\
\hline & Recovery (\%) & RSD ( $\%)$ & Recovery (\%) & RSD (\%) & \\
\hline Diflufenican & 99 & 18 & 3 & 14 & 102 \\
\hline Chlorpyrifos & 79 & 16 & 3 & 10 & 82 \\
\hline Phosmet & 93 & 20 & 2 & 20 & 95 \\
\hline Diuron & 81 & 17 & 2 & 20 & 83 \\
\hline Terbuthylazine & 96 & 13 & 3 & 15 & 99 \\
\hline Dimethoate & 70 & 11 & 3 & 16 & 73 \\
\hline Amitrole & 8 & 5 & 2 & 40 & 10 \\
\hline
\end{tabular}

Notes: RSD, Relative standard deviation.

"Liquid Chromatography coupled with mass spectrometry working in positive electrospray ionization (ESI).

10-25-50-75-100-150 and $300 \mathrm{ng} \cdot \mathrm{mL}^{-1}$ concentration levels. Seven pesticides presented correlation coefficients higher than 0.99 and only one presented poor linearity in the range studied (Oxyfluorfen). The results are shown in Table 3.

The precision of the method was studied by performing repeatability experiments that were evaluated by applying the extraction procedure five times to the same sample. The repeatability was acceptable for all analytes so that RSDs were not higher than $20 \%$. Diflufenican was an exception, because samples at a concentration level of $20 \mu \mathrm{g} \cdot \mathrm{kg}^{-1}$ presented 25\% RSDs as the most unfavorable case.

The method accuracy was evaluated through recovery studies and was determined by running five extractions from olive samples spiked with pesticides at 20 and $100 \mu \mathrm{g} \cdot \mathrm{kg}^{-1}$ concentration levels as described in section 2.4. Mean recoveries lie within an acceptable range according to EU Guidelines, from 73 to $114 \%$. Table 6 shows an average of recoveries at two concentration levels. The recoveries of Amitrole and Oxyfluorfen were discarded due to the fact that its LODs and LOQs were higher than the concentration levels evaluated.

The limits of detection and quantification were estimated as the lowest concentration level to reach a signal-to-noise ratio of three $(S / N=3)$ and ten $(S / N=10)$, respectively. Table 6 summarizes the values obtained during the validation of the method.

\subsection{Application of the method to olive samples}

To check the validity of the method, 25 samples of olives from different points of the Andalusian geography were analyzed by the proposed method. Some pesticides were found in the samples but none were above the Maximum Residue Limit (MRL) established by current European Legislation (DG SANCO, 2013). Particularly, Dimethoate and Terbuthylazine were detected in some samples, but the results were lower than $15 \mu \mathrm{g} \cdot \mathrm{kg}^{-1}$. The results are shown in Table 7.

TABLE 6. Average recovery (\%), RSD (\%) LODs and LOQs obtained by extraction of samples spiked at 20 and $100 \mu \mathrm{g} \cdot \mathrm{kg}^{-1}$ levels $(\mathrm{n}=5)$

\begin{tabular}{|c|c|c|c|c|c|c|}
\hline \multirow[b]{3}{*}{ Pesticide } & \multicolumn{4}{|c|}{ Spiking Levels } & \multirow[b]{3}{*}{$L O D s\left(\mu \mathrm{g} \cdot \mathrm{kg}^{-1}\right)$} & \multirow[b]{3}{*}{$L O Q s\left(\mu \mathrm{g} \cdot \mathrm{kg}^{-1}\right)$} \\
\hline & \multicolumn{2}{|c|}{$100\left(\mu \mathrm{g} \cdot \mathrm{kg}^{-1}\right)$} & \multicolumn{2}{|c|}{$20\left(\mu \mathrm{g} \cdot \mathrm{kg}^{-1}\right)$} & & \\
\hline & Recovery (\%) & RSD (\%) & Recovery (\%) & RSD (\%) & & \\
\hline Diflufenican & 79 & 10 & 82 & 14 & 0.40 & 1.00 \\
\hline Chlorpyrifos & 83 & 10 & 80 & 20 & 4.00 & 8.00 \\
\hline Phosmet & 98 & 4 & 114 & 18 & 0.20 & 0.80 \\
\hline Diuron & 73 & 11 & 93 & 20 & 0.30 & 0.80 \\
\hline Terbuthylazine & 96 & 4 & 94 & 18 & 0.03 & 0.06 \\
\hline Dimethoate & 74 & 10 & 74 & 10 & 0.40 & 0.80 \\
\hline Amitrole & 14 & 17 & n.d. & n.d. & 10.00 & 30.00 \\
\hline Oxyfluorfen & n.d. & n.d. & n.d. & n.d. & 100.00 & 200.00 \\
\hline
\end{tabular}

Notes: RSD, Relative standard deviation.

$L O D s$ and $L O Q s$ were calculated using a level of $0.1 \mu \mathrm{g} \cdot \mathrm{kg}^{-1}$.

LOD, limit of determination; LOQ, limit of quantification. 
TABLE 7. Average results (average \pm relative standard deviation) obtained after application of the liquid extraction surface analysis $(n=3)$ in 25 olive samples that were collected from the soil. Samples were analyzed by LC-ESI-MS/MS in positive mode (results are expressed in $\mu \mathrm{g} \cdot \mathrm{kg}^{-1}$ )

\begin{tabular}{llr}
\hline Sample & \multicolumn{1}{c}{ Pesticides } & $\boldsymbol{\mu g} \cdot \mathbf{k g}^{\mathbf{- 1}}$ \\
\hline Sample 2 & Terbuthylazine & $14.59 \pm 1.35$ \\
Sample 5 & Terbuthylazine & $11.67 \pm 2.55$ \\
& Dimethoate & $3.51 \pm 0.64$ \\
Sample 8 & Terbuthylazine & $8.31 \pm 1.09$ \\
Sample 22 & Diflufenican & $6.09 \pm 2.54$ \\
Sample 25 & Dimethoate & $7.00 \pm 1.33$ \\
\hline
\end{tabular}

The rest of pesticides evaluated were not detected in these samples.

\section{CONCLUSIONS}

A new rapid, simple and economical method, based on liquid extraction solvent analysis of the olive surface has been developed. The method employs $\mathrm{MeCN}$ as the extraction solvent with an automatic shaker. Pesticide quantification required matrix-matched calibration in order to avoid interference that could mask the correct determination of pesticides. To optimize the method, several variables were studied such as the type of solvent, the extraction time, the oscillation speed or the number of extractions. Optimal conditions for the liquid extraction surface analysis method were reached with $\mathrm{MeCN}$ as solvent extraction $(1: 1 \mathrm{w} / \mathrm{v}), 10$ minutes of shaking at $750 \mathrm{opm}$ and a single extraction. The results of the validation of the method in terms of linearity, repeatability, selectivity and recoveries were evaluated from samples spiked at two concentration levels, obtaining results between 73 and $114 \%$.

The new proposed method is more rapid and simple than other pesticide extraction methods, because it uses a smaller number of analytical steps and consumes less volume of extraction solvent. Moreover, the new method is more representative because it uses a higher amount of sample (30 g).

Finally, the LODs and LOQs reached were small enough to apply this method in routine laboratories. Nevertheless, Oxyfluorfen and Amitrole could not be successfully quantified by this procedure because of their high LODs and LOQs.

\section{ACKNOWLEDGMENTS}

This work was supported by a $\mathrm{PhD}$ fellowship of the "Instituto Nacional de Investigación y Tecnología Agraria y Alimentaria (INIA)", and the Project "INIA RTA 2006-00097-00-00".

\section{REFERENCES}

Amvrazi EG, Albanis TA. 2006. Multiresidue method for determination of 35 pesticides in virgin olive oil by using liquid-liquid extraction techniques coupled with solid-phase extraction clean up and gas chromatography with nitrogen phosphorus detection and electron capture detection. $J$. Agric. Food Chem. 54, 9642-51. http://dx.doi.org/10.1021/ jf061375s.

Anastassiades M, Lehotay SJ, Štajnbaher D, Schenck FJ. 2003. Fast and easy multiresidue method employing acetonitrile extraction/partitioning and "dispersive solid-phase extraction" for the determination of pesticide residues in produce. J. AOAC Int. 86, 412-31.

Angioni A, Porcu L, Pirisi F. 2011. LC/DAD/ESI/MS method for the determination of imidacloprid, thiacloprid, and spinosad in olives and olive oil after field treatment. $J$. Agric. Food Chem. 59, 11359-66. http://dx.doi.org/10.1021/ jf2028363.

Aramendía MA, Borau V, Lafont F, Marinas A, Marinas JM, Moreno JM, Urbano FJ. 2007. Determination of herbicide residues in olive oil by gas chromatography-tandem mass spectrometry. Food Chem. 105, 855-61. http://dx.doi. org/10.1016/j.foodchem.2007.01.063.

Ballesteros E, García Sánchez A, Ramos Martos N. 2006. Simultaneous multidetermination of residues of pesticides and polycyclic aromatic hydrocarbons in olive and olivepomace oils by gas chromatography/tandem mass spectrometry. J. Chromatogr. A, 1111, 89-96. http://dx.doi.org/ 10.1016/j.chroma.2006.01.101.

Cervera M, Portolés T, Pitarch E, Beltrán J, Hernández F. 2012. Application of gas chromatography time-of-flight mass spectrometry for target and non-target analysis of pesticide residues in fruits and vegetables. J. Chromatogr. A, 1244, 168-177. http://dx.doi.org/10.1016/j.chroma.2012.04.063.

Covas, M. 2007. Olive oil and the cardiovascular system. Pharmacol. Res. 55, 175-186. http://dx.doi.org/10.1016/j. phrs.2007.01.010

Cunha SC, Lehotay SJ, Mastovska K, Fernandes JO, Beatriz M, Oliveira P. 2007a. Evaluation of the QuEChERS sample preparation approach for the analysis of pesticide residues in olives. J. Sep. Sci. 30, 620-632. http://dx.doi. org/10.1002/jssc. 200600410 .

Cunha SC, Fernandes JO, Beatriz M, Oliveira PP. $2007 \mathrm{~b}$. Comparison of matrix solid-phase dispersion and liquidliquid extraction for the chromatographic determination of fenthion and its metabolites in olives and olive oils. Food Addit. Contam. 24, 156-164. http://dx.doi.org/10.1080/ 02652030600970374

Cunha SC, Fernandes JO, Beatriz M, Oliveira PP. 2007c. Determination of phosmet and its metabolites in olives by matrix solid-phase dispersion and gas chromatographymass spectrometry. Talanta, 73, 514-522. http://dx.doi.org/ 10.1016/j.talanta.2007.04.014.

DG SANCO. 2013. EU pesticides database. pesticide UE-MRLs: Regulation (EC) no 396/2005. Active substances: Regulation (EC) no 1017/2009. Retrieved from http://ec.europa.eu/ sanco_pesticides/public/?event $=$ homepage $\&$ CFID $=68165$ $1 \&$ CFTOKEN $=66471355 \&$ jsessionid $=08 \mathrm{a} 0 \mathrm{a} 5 \mathrm{~b} 8 \mathrm{c} 1773 \mathrm{dd} 5$ 6e8f27333345207652c2TR.

Eikel D, Henion J. 2011. Liquid extraction surface analysis (LESA) of food surfaces employing chip-based nano-electrospray mass spectrometry. Rapid Commun. Mass Spectrom. 25, 2345-2354. http://dx.doi.org/10.1002/rcm.5107.

European Committee for Standardization. 2013. CEN standard method EN 15662: Food of plant origin - determination of pesticide residues using $G C-M S$ andlor $L C-M S /$ $M S$ following acetonitrile extraction/partitioning and clean up by dispersive SPE-QuEChERS method. Retrieved from https://www.google.es/url?sa $=\mathrm{t} \& \mathrm{rct}=\mathrm{j} \& \mathrm{q}=\&$ esrc $=$ s\&source $=$ web $\& c d=1 \& c a d=$ rja\&ved $=0 C D c Q F j A A \& u r l=$ http $\% 3 \mathrm{~A} \% 2 \mathrm{~F} \% 2 \mathrm{Fwww}$.cen.eu $\% 2 \mathrm{Fcen} \% 2 \mathrm{Fproducts} \% 2 \mathrm{~F}$ en $\% 2$ Fpages $\% 2$ Fdefault.aspx\&ei=WLRyUrjVKceR7Aa I7YDoAw\&usg=AFQjCNGQvfsZyiJUoTaNOxlai5qKS hrEXg.

Ferrer C, Gómez MJ, García-Reyes JF, Ferrer I, Thurman EM, Fernández-Alba AR. 2005. Determination of pesticide residues in olives and olive oil by matrix solid-phase dispersion followed by gas chromatography/mass spectrometry and liquid chromatography/tandem mass spectrometry. $J$. Chromatogr. A, 1069, 183-194. http://dx.doi.org/10.1016/j. chroma.2005.02.015. 
García-Reyes JF, Ferrer C, Gómez-Ramos MJ, Fernández-Alba AR, García-Reyes JF, Molina-Díaz A. 2007a. Determination of pesticide residues in olive oil and olives. Trac-Trends Anal. Chem. 26, 239-251. http://dx.doi.org/10.1016/j.trac. 2007.01.004.

García-Reyes JF, Hernando MD, Molina-Díaz A, FernándezAlba AR 2007b. Comprehensive screening of target, nontarget and unknown pesticides in food by LC-TOF-MS. Trac-Trends Anal. Chem. 26, 828-841.

Gilbert-López B, García-Reyes JF, Fernández-Alba AR, MolinaDíaz A. 2010a. Evaluation of two sample treatment methodologies for large-scale pesticide residue analysis in olive oil by fast liquid chromatography-electrospray mass spectrometry. J. Chromatogr. A, 1217, 3736-3747. http://dx.doi.org/ 10.1016/j.chroma.2010.04.025.

Gilbert-López B, García-Reyes JF, Lozano A, Fernández-Alba AR, Molina-Díaz A. 2010b. Large-scale pesticide testing in olives by liquid chromatography-electrospray tandem mass spectrometry using two sample preparation methods based on matrix solid-phase dispersion and QuEChERS. $J$. Chromatogr. A, 1217, 6022-6035. http://dx.doi.org/10.1016/ j.chroma.2010.07.062.

Gilbert-López B, García-Reyes JF, Mezcua M, Ramos-Martos N, Fernández-Alba AR, Molina-Díaz A. 2010c. Multiresidue determination of pesticides in fruit-based soft drinks by fast liquid chromatography time-of-flight mass spectrometry. Talanta, 81, 1310-1321. http://dx.doi.org/ 10.1016/j.talanta.2010.02.026.

Guardia Rubio M, Ruiz Medina A, Molina Díaz A, Fernández de Córdova ML. 2006. Determination of pesticides in washing waters of olive processing by gas chromatography-tandem mass spectrometry. J. Sep. Sci. 29, 1578-1586. doi:10.1002/ jssc. 200500269.

Guardia Rubio M, Ayora-Cañada MJ, Ruiz-Medina A. 2007a. Effect of washing on pesticide residues in olives. J. Food Sci. 72, 139-143.

Guardia Rubio M, Ruiz Medina A, Pascual Reguera M, Fernández de Córdova M. 2007b. Multiresidue analysis of three groups of pesticides in washing waters from olive processing by solid-phase extraction-gas chromatography with electrón capture and thermionic specific detection. Microchem. J. 85, 257-264.

Guardia Rubio M, Marchal-López RM, Ayora-Cañada MJ, Ruiz-Medina A. 2007c. Determination of pesticides in olives by gas chromatography using different detection systems. J. Chromatogr: A, 1145, 195-203. http://dx.doi.org/ 10.1016/j.chroma.2007.01.068.

Kmellár B, Fodor P, Pareja L, Ferrer C, Martínez-Uroz MA, Valverde A, Fernandez-Alba AR. 2008. Validation and uncertainty study of a comprehensive list of 160 pesticide residues in multi-class vegetables by liquid chromatographytandem mass spectrometry. J. Chromatogr. A, 1215, 37-50.

Koesukwiwat U, Lehotay SJ, Miao S, Leepipatpiboon N. 2010. High throughput analysis of 150 pesticides in fruits and vegetables using QuEChERS and low-pressure gas chromatography-time-of-flight mass spectrometry. J. Chromatogr. A, 1217, 6692-6703.

Lehotay SJ, Maštovská K, Lightfield AR. 2005. Use of buffering and other means to improve results of problematic pesticides in a fast and easy method for residue analysis of fruits and vegetables. $J$. $A O A C$ Int . 88, 615-629.

Lehotay SJ, O’Neil M, Tully J, García AV, Contreras M, Mol H, Parker A. 2007. Determination of pesticide residues in foods by acetonitrile extraction and partitioning with magnesium sulfate: Collaborative study. J. AOAC Int. 90, 485-520.

Lehotay SJ, Son KA, Kwon H, Koesukwiwat U, Fu W, Mastovska, K, Leepipatpiboon N. 2010. Comparison of QuEChERS sample preparation methods for the analysis of pesticide residues in fruits and vegetables. J. Chromatogr. A, 1217, 2548-2560

Long R, Gan J, Nett M. 2005. Pesticide choice: Best management practice (BMP) for protecting surface water quality in agriculture. University of California. Division of Agriculture and Natural Resources. Publication Number: 8161, 8161 doi:ISBN-13: 978-1-60107-330-3.

Ruiz-Canela M, Martínez-González MA. 2011. Olive oil in the primary prevention of cardiovascular disease. Maturitas, 68, 245-250.

Sánchez AG, Martos NR, Ballesteros E. 2006. Multiresidue analysis of pesticides in olive oil by gel permeation chromatography followed by gas chromatography-tandem mass-spectrometric determination. Anal. Chim. Acta, 558, 53-61. http://dx.doi.org/10.1016/j.aca.2005.11.019.

Wilkowska A, Biziuk M. 2011. Determination of pesticide residues in food matrices using the QuEChERS methodology. Food Chem. 125, 803-812.

Yuzhou L, Xin D. 2012. Methodology for evaluating pesticides for surface water protection I: Initial screening. Department of Pesticide Regulation. Environmental Monitoring Branch. 